the angry bees ; cautiously emerging from their sheets on the high road, the first person they encountered was their Colonel and his family driving to Church. The finale may be imagined!

I have always been fond of sleeping out during the hot weather, sub Fove frigido, or rather torrido, and used to have a sooráee (a porous earthen water bottle) capped by a tumbler, on the ground by my side.

One night $I$ awoke to drink and, half awake, lifting the sooráee on to my naked knee proceeded to fill the tumbler. In a moment I felt as if a red hot poker had been freely applied to my knee, and, thinking that $I$ had been stung by a snake, rushed into the house for a light, and a dose of sal volatile. I was now wide awake, and returned with the light to examine into matters, and then I found a large centipede coiled round the bottom of the sooráee, whither it had come for coolness or a drink, or both. It was six inches long. Judging from the size of the burn (for I bore the large red mark for many days), I inferred that I had not been bitten, but that the whole animal was acrid.

Peshawar

H. F. HUTCHINSON

\section{Spider's Web, New Caledonia}

CONSUl Layard's account of the spiders' webs of the Polynesian Arachnids (NATURE, vol. xx. p. 456) reminds one of the colonial enthusiasm of certain fair ladies in Mauritius seventy years ago, previous to the capture of that island by General Abercrombie.

Throughout the Mascarene group are numerous species of Araneidea, among which Epeira inaurata and E. mauricia are pre-eminent, their bright yellow webs being conspicuously stretched between the pointed leaves of the agaves and pricklypears. Taking advantage of these "grandes toiles verticales à fils jaunes, soyeux et susceptibles d'être travaillés; sous le gouverneur-général Decaen, les dames créoles de l'île de France isserent avec les fils de ces belles aranéides une paire de gants dont elles firent hommage à l'impératrice." S. P. OLIver

October 5

\section{Change of Colour in Frogs}

CAN any of your readers tell me if it is a fact that frogs change their colour before a change takes place in the weather?

A few days ago I was told at a village in Worcestershire, during heavy rain, that it would be fine to-morrow because a frog had been seen turning yellow. The fine weather came. I was informed that frogs become dark-coloured before wet weather sets in.

Junior United Service Club, September 30

W. J. Chamberlayne

["The changes which the colour of the frog undergoes both in intensity and hue from the variation of temperature, the presence and absence of light. . . although certainly much less striking and considerable, are scarcely less varied than those exhibited by the chameleon."-Bell, "British Reptiles."]

\section{SUBYECT-INDEXES TO TRANSACTIONS OF} LEARNED SOCIETIES

$\mathrm{WE}$ all remember the excellent paper read at the Oxford Conference by Mr. J. B. Bailey, sublibrarian at the Radcliffe Library, upon the advantage of a subject-index to scientific periodicals. Mr. Bailey spoke with just praise of the splendid alphabetical catalogue issued by the Royal Society, but observed that from the nature of the case this is "nearly useless in making a bibliography of any given subject, unless one is familiar with the names of all the authors who have written thereon." This is manifestly the case. As an illustration both of the value and the deficiencies of the Royal Society's index, I may mention that while on the one hand it has enabled me to discover that my father, chiefly celebrated as a philologist, has written a paper on the curious and perplexing subject of the formation of ice at the bottoms of rivers, the existence of which was wholly unknown to his family, it does not, on the other

${ }^{x}$ By Richard Garnett, Superintendent of the Reading Room, British
Museu Museum. Read at the March monthly meeting of the Library Association of the United Kingdom. Contributed by the Author. hand, assist me to ascertain, without a most tedious search, what other writers may have investigated the subject, or consequently how far his observations are in accordance with theirs. Multiply my little embarrass ment by several hundred thousand, and you will have some idea of the amount of ignorance which the classified index suggested by $\mathrm{Mr}$. Bailey would enlighten. We may well believe that the only objection he has heard alleged is the magnitude of the undertaking, and must sympathise with his conviction that, granting this, it still ought not to be put aside merely because it is difficult. I hope to point out, however, that so far as concerns the scientific papers, to which alone Mr. Bailey's proposal relates, the difficulty has been over-estimated, that the literary compilation need encounter no serious obstacle, and that the foundation might be laid in a short time by a single competent workman, such as $\mathrm{Mr}$. Bailey himself. Of an index to literary papers I shall speak subsequently; and, there, I must acknowledge, the difficulties are much more formidable. But as regards scientific papers, it appears to me that the only considerable impediment is the financial. When the others are overcome, then, and not till then, we shall be in a favourable position for overcoming this also. The reason why the formation of a classified index to scientific papers is comparatively easy, is that the groundwork has been already provided by the alphabetical index of the Royal Society. We have the titles of all scientific papers from 1800 to 1865 before us, and shall soon have them to 1873 . Though it might be interesting, it is not essential to go further back. We have now to consider how best to distribute this alphabetical series into a number of subject-indexes. To take the first step we merely require a little money (the first condition of success in most undertakings), and some leisure on the part of a gentleman competent to distinguish the grand primary divisions of scientific research from each other, and avoid the errors which cataloguers have been known to commit in classing the star-fish with constellations, and confusing Plato the philosopher with Plato a volcano in the moon. I need only say that very many of our body would bring far more than this necessary minimum of scientific knowledge to the task. I may instance Mr. Bailey himself. The money would be required to procure two copies of the alphabetical index (which, however, the Royal Society would very likely present), and to pay an assistant for cutting these two copies up into strips, each strip containing a single entry of a scientific paper, and pasting the same upon cardboard. It would be necessary to have two copies of the alphabetical catalogue, as this is printed on both sides of the paper; and as the name of the writer is not repeated at the head of each of his contributions, and would therefore have to be written on the card, close supervision would be required, or else a very intelligent workman. When this was done, the entire catalogue would exist upon cards, in a movable form instead of an immovable. The work of the arranger or arrangers would now begin. All that he or they would have to do would be to write somewhere upon the card, say in the left hand upper corner, the name of the broad scientific division, such as astronomy, meteorology, geology, to which the printed title pasted upon the card appertained, and to put each into a box appropriated to its special subject, preserving the alphabetical order of each division. We should then have the classed index already in the rough, at a very small relative expenditure of time, money, and labour. For the purposes of science, however, a more minute subdivision would be necessary. Here the functions of our Council would come into play, and it would have a great opportunity of demonstrating its usefulness as an organising body by inducing, whether by negotiation with individuals or with scientific corporations like the Royal Society, competent men of science to undertake the task of classifying the papers relating to 
their own special studies. Men of science, we may be certain, are fully aware of the importance of the undertaking, which is indeed designed for their special benefit; and although they are a hard-worked race, I do not question that a sufficient number of volunteers would be forthcoming. When one looks, for example, at the immense labour of costly and unremunerated research undertaken by a man like the late Mr. Carrington, one cannot doubt that men will be found to undertake the humbler but scarcely less useful and infinitely less onerous task of making the discoveries of the Carringtons generally available. I am sure, for instance, that such men as Mr. Knobel and Mr. Carruthers would most readily undertake the classification of the astronomical and the botanical departments respectively, provided that their other engagements allowed, as to which, of course, I cannot affirm anything. Supposing our scientific editors found, they would proceed exactly in the same manner as the editor who had already accomplished the classification in the rough. Each would take the cards belonging to his own section, and would write opposite to the general subject title written by the first classifier the heading of the minor sub-section to which he thought it ought to be referred; thus, opposite Botany-Lichen, and so on. $\mathrm{He}$ would then put the title into the box or drawer belonging to its sub-section, and when the work was complete we should have the whole catalogue in a classified form, digested under a number of sub-headings. Some preliminary concert among the scientific editors would, no doubt, be necessary, and a final revision in conformity with settled rules. It might be questioned, for example, whether a dissertation on camphor properly belonged to botany, chemistry, or materia medica; whether the subject of the gymnotus was ichthyological, anatomical, or electrical; whether in such dubious cases a paper should be entered more than once. It would save time and trouble if these points could be determined before the classification in the rough was commenced; in any case considerable delay from unavoidable causes must be anticipated. It is to be remembered, on the other hand, that the work could, under no circumstances, be completed until the publication of the Royal Society's alphabetical index of papers from 1865 to 1873 was finished, which, I suppose, will not be the case for two or three years. There will, therefore, be sufficient time to meet unforeseen causes of delay. If the classified index could be ready shortly after the alphabetical, if we could show the world that the work was not merely talked about as desirable, but actually done in so far as depended upon ourselves and the representatives of science ; that it already existed in the shape of a card catalogue, and needed nothing but money to be made accessible to everybody - then we should be in a very different position from that which we occupy at present. I cannot think that so much good work would be allowed to be lost. The catalogue, not being confined to papers in the English language, would be equally useful in every country where science is cultivated, and would find support all over the civilised world. Either from the Government, or from learned societies, or the universities, or the enterprise of publishers, or the interest of individual subscribers, or private munificence, means would, sooner or later, be forthcoming to bring the work out, and thus erect a most substantial monument to the utility of our Association. It would obviously be important to provide that scientific papers should be indexed not only for the past, but for the future. If, as I trust, the Royal Society intends to continue the publication of its alphabetical index from time to time, the compilers of the classified index will continue to enjoy the same facilities as at present. There must be some very effectual machinery at the Society for registering new scientific papers as they are published. What it is we may hope to learn from our colleague, its eminent librarian, who must be the most com- petent of all authorities on the subject. Mr. Bailey draws attention to several scientific periodicals as useful for bibliographical purposes, and I may mention one which seems to be very complete. ${ }^{1}$ It is published at Rome. The number for last December, which I have just seen, is so complete that, among a very great number of scientific papers from all quarters, it records those on the telephone and the electric light, in the "Companion to the British Almanac," which, I think, had then been only announced here, not published, omitting the other contributions as non-scientific. It further gives a complete index to the contents of the Revista Cientifica, a Barcelona periodical, which had apparently just reached the editor, from its commencement in the preceding April. By this list I learn that the electric pen, the subject of our colleague Mr. Frost's recent paper, had been the theme of a communication to a Barcelona society in May last. It certainly seems as if any library that took this periodical in, and transcribed the entries in its bibliographical section on cards properly classed, would be able to keep up a pretty fair subjectindex to scientific ipapers for the future. I must, in conclusion, say a few words on a subject-index to the transactions of literary societies. The prospect is here much more remote, from the want of the almost indispensable ground-work of a general alphabetical index. We have seen what an infinity of trouble in collecting, in cataloguing, and in transcribing will be saved by the Royal Society's list in the case of scientific papers, and are in a position to appreciate the impediments which must arise from the want of one in this instance. The work could be done by the British Museum if it had a proportionate addition to its staff, or by a continuance of the disinterested efforts which are now devoted to the continuation of Mr. Poole's index to periodicals. Failing these, the most practical suggestion appears to me Mr. Bailey's, that the undertaking might be to a considerable extent promoted by the respective societies themselves. If the secretaries of the more important of these bodies would cause the titles of the papers occurring in their transactions to be transcribed upon cards and deposited with this Association, we should accumulate a mass of material worth working upon, and which might be arranged while awaiting a favourable opportunitity for publication. In some instances even more might be done. The library of the Royal Asiatic Society, for example, contains not merely its own transactions, but those of every important society devoted to Oriental studies, as well as all similar periodicals. Our friend, Mr. Vaux, could probably, in process of time, not only procure transcripts of the papers contained in these collections, but could induce competent Orientalists to prepare a scheme of classification, and such a classified list, complete in itself and of no unwieldy magnitude, could be published as a sample and forerunner of the rest. The initiative in such proposals, as well as those referring to scientific papers, should be taken by our Association, which can negotiate with eminent men and learned bodies upon equal terms, and speak with effect where the voice of an individual would be lost. The desideratum of a classed index, in a word, affords our Society a great opportunity of distinguishing itself. It is this aspect of the matter, no less than the importance of the matter itself that has encouraged me to bring it under your notice.

$$
\text { ON VARIABLE STARS }
$$

$\mathrm{T} \mathrm{T}$ had long been known that certain stars greatly varied in brightness and some observations had been made concerning them, but it was reserved to the Herschels to pave the way for practical investigators. Notwithstand-

I Bullettino di brbliografia e di storia delle scienze matematiche e fisiche. Pubbl. da B. Boncompagni; Rome, I868, \&c. 